\title{
Uterine Artery Doppler study and Serum B-Human Chorionic Gonadotropin as Predictors of Preeclampsia
}

Afaf A. Ismail, Aziza Nassef, Mona El Desouky

Department of Obstetrics and Gynecology, Faculty of Medicine, Al-Azhar University

*Corresponding Author: Afaf A. Ismail, Phone No.: (+2) 01006602136, E-mail: afaf@ doctor.com

\begin{abstract}
Background: preeclampsia (PE) is defined as the presence of high blood pressure (BP > 140/90 $\mathrm{mmHg}$ ) after 20 weeks gestation, in a previously normotensive non-proteinuric patient with one or more of the following: significant protienuria (>0.3 g/24 h), maternal organ dysfunction or utero- placental dysfunction.
\end{abstract}

Aim of the Work: screening of preeclampsia using serum $\beta$-HCG titre at 11-14 weeks of gestation and uterine artery Doppler study at 11-14 weeks and 22-24 weeks of gestation.

Patients and Methods: the study was a prospective. It was conducted at the outpatient clinics of Obstetrics and Gynecology of Al-Zahraa University Hospital, Al-Azhar University during the period from February 2017 to April 2018.

Results: the uterine artery pulsatility index (PI) and resistance index (RI) of both uterine artery were significantly high in those patients who developed PE. In the uterine artery Doppler study at 11-14 weeks of gestation, the mean PI and RI of both right and left uterine arteries were significantly different between the two groups, PI and RI were higher in PE group, the mean of right uterine artery PI in PE group was $2.39 \pm$ 0.38 VS $1.69 \pm 0.34$ in non PE group. It was statistically highly significant (P value was 0.004$)$. The maternal serum $\beta$-HCG titre was insignificantly different in those who developed preeclampsia and others.

Conclusion: the maternal uterine artery PI and RI in early pregnancy (11-14 weeks of gestation) and in mid pregnancy (22-24 weeks of gestation) were increased and associated with occurrence of preeclampsia.

Keywords: Uterine Artery Doppler - Serum BHCG - Notch- Preeclampsia

\section{INTRODUCTION}

Early onset preeclampsia is usually defined as preeclampsia that develops before 34 weeks gestation, late onset preeclampsia develops at or after 34 weeks gestation (1). Maternal endothelial cell dysfunction is the key event for the clinical adverse presentation of preeclampsia. Preeclampsia decrease the utero-placental blood flow about $30-50 \%$ compared to the normal pregnancy ${ }^{(2)}$.

The mechanism of endothelial cell dysfunction is unclear till now, but the evidence suggests that the placenta is the key factor that may leads to pathophysology of preeclampsia, this is based on the inability of the trophoblast to invade the myometrium properly leading to poor remodeling of spiral artery ${ }^{(3)}$.

In preeclampsia, histological examination of the placenta reveals focal cellular necrosis in the syncytiotrophoblast and increase mitotic activity with cellular proliferation in the cytotrophoblast. In addition the proliferating trophoblast in severe preeclampsia is transformed rapidly into syncytiotrophoblast within 72 hours. The normal placental differentiates in pregnancy with the cytotrophoblast dominant in early gestation and the syncytiotrophoblast dominant in late pregnancy. Placental vascular damage causing impaired oxygen supply could leads to increased production of human chorionic gonadotropin by hyperplastic cytotrophoblastic cells ${ }^{(4)}$. Preeclampsia occurred in ten million women per year worldwide, about 76,000 pregnant women die per year from preeclampsia or its related complications and 500,000 of babies die from these disorders each year (5).

The human chorionic gonadotropin (HCG) is a glycoprotein that is produced by the placenta from syncytiotrophoblast cells. Maternal serum HCG peaks at 8-10 weeks of gestation and then decreases to become a plateau at $18-20$ weeks of gestation ${ }^{(\boldsymbol{6})}$.

It has been hypothesized that HCG may act to promote uterine vasodilatation and myometrial smooth muscle relaxation ${ }^{(7)}$. Also, HCG might be involved in the development of preeclampsia, it may promotes angiogenesis ${ }^{\left({ }^{(8)}\right.}$. The high serum HCG level may be a helpful marker in the diagnosis and clinical management of preeclampsia (9). Also unexplained $\mathrm{HCG}$ elevation during the second trimester may be associated with many adverse pregnancy outcomes such as preeclampsia and fetal growth restriction ${ }^{(\mathbf{1 0})}$.

Doppler ultrasound may help in the management of high-risk pregnancies. The use of Doppler imaging permits non-invasive evaluation of the uteroplacental circulation ${ }^{(11)}$.

In the non-pregnant women, there is a rapid rise and fall in uterine artery flow velocity during systole and a "notch" in the descending wave form in early diastole. During pregnancy, there is a significant increase in uterine artery compliance between 8 and 16 weeks gestation ${ }^{(12)}$.

The inadequate placental perfusion precede clinical manifestations of preeclampsia 
and it may be detected by Doppler ultrasonography ${ }^{(\mathbf{1 3})}$. Uterine artery Doppler screening of high risk women (eg, history of preeclampsia or hypertension, prior fetal growth retardation, or stillbirth) can predict those at high risk for preeclampsia. This could increase the surveillance and interventions that might improve the outcomes of preeclampsia ${ }^{(14)}$.

\section{AIM OF THE WORK}

The aim of this study is screening of preeclampsia using serum $\beta$-HCG titre at $11-14$ weeks of gestation and uterine artery Doppler study at 11-14 weeks and 22-24 weeks of gestation.

\section{PATIENTS AND METHODS}

\section{Study design}

Setting

A prospective study

This study was conducted at the Outpatient Clinics of Obstetrics and Gynecology of Al-Zahraa University Hospital, Al-Azhar University during the period from February 2017 to April 2018.

\section{Study population}

Sixty primigravidae with singleton pregnancy women were included. Exclusion criteria were medical disorders as diabetes mellitus (DM), hypertension, renal or hepatic diseases, fetal anomalies, and dead fetus.

Ethical consideration and written informed consent:

An approval of the study was obtained from Al- Azhar University Academic and Ethical Committee. Every woman signed an informed written consent for acceptance of the process.

\section{Method:}

All women were subjected to detailed history taking with more concern to: Personal history including: name, age, occupation, etc. Menstrual history (date of LNMP to confirm gestational age, etc.). History of the current pregnancy (to exclude any medical disorders). Past history to exclude DM, HTN, cardiac problem or other serious illness, family history,

Complete clinical examination was done including: General examination (blood pressure, pulse, body weight, height and BMI, etc.), chest and cardiac examination, abdominal examination were done.

Investigations:

All women were subjected to routine antenatal investigations including: $\mathrm{ABO}, \mathrm{Rh}$ group, $\mathrm{CBC}$, fasting, postprandial blood sugar and complete urine analysis. Measurement of maternal serum $\beta$-HCG level and uterine artery Doppler study by transabdominal ultrasound were done for all cases at 11-14 weeks of gestation (confirmed by the date of last menstrual period (LMP) and by early ultrasound scanning). Then the uterine artery Doppler assessment was repeated during the 2224 weeks of gestation. Follow up of all cases was done until delivery to assess occurrence of preeclampsia.

\section{Ultrasonography assessment:}

At 11-14 weeks of gestation transabdominal ultrasound examination was performed with the woman placed in a recumbent or semi recumbent position and carried out for routine first trimester scanning (fetal CRL, mean gestational sac diameter and diagnosis of any major fetal abnormalities). Then a sagittal section of the uterus was obtained, and the cervical canal was identified. Subsequently, the transducer was gently tilted from side to side and color flow mapping was used to identify each uterine artery along the side of the cervix and uterus at the level of the internal cervical os. Pulsed wave Doppler imaging was used with the sampling gate set at 2 $\mathrm{mm}$ to cover the whole vessel. When at least three similar consecutive waveforms had been clearly visualized the uterine artery pulsatility index (PI) and uterine artery resistance index (RI) were measured automatically, and the mean uterine artery PI and uterine artery RI of the left and right arteries were calculated. Also, the presence of the notch was assessed. The measurements were repeated three times then the mean values were taken.

Then, the uterine artery Doppler study was repeated at 22-24 week for measurement of uterine artery PI and RI.

The used equipment was LOGIQ V5 and the printer was SONY UPP-110.

\section{Serum $\beta$-HCG titre:}

At 11-14 weeks gestation, five cubic millimeters of maternal blood were withdrawn by venipuncture from each case; the collected blood was allowed to clot into a non-heparinized tube. The serum samples were centrifuged for 10 minutes, and the serum was separated, transferred to a clean storage tubes by sterile pipette and was immediately stored frozen at $-20^{\circ} \mathrm{C}$. A labeled ticket with the patient name and number was placed on each tube for evaluation of maternal serum $\beta$-HCG level. The measured concentration of $\beta$-HCG were then correlated with pregnancy outcome.

The $\beta$-HCG was measured using the AccuBindTM microwells, immunoenzymometric assay, Mono bind inc., Lake Forest, USA. 
ejhm.journals.ekb.eg

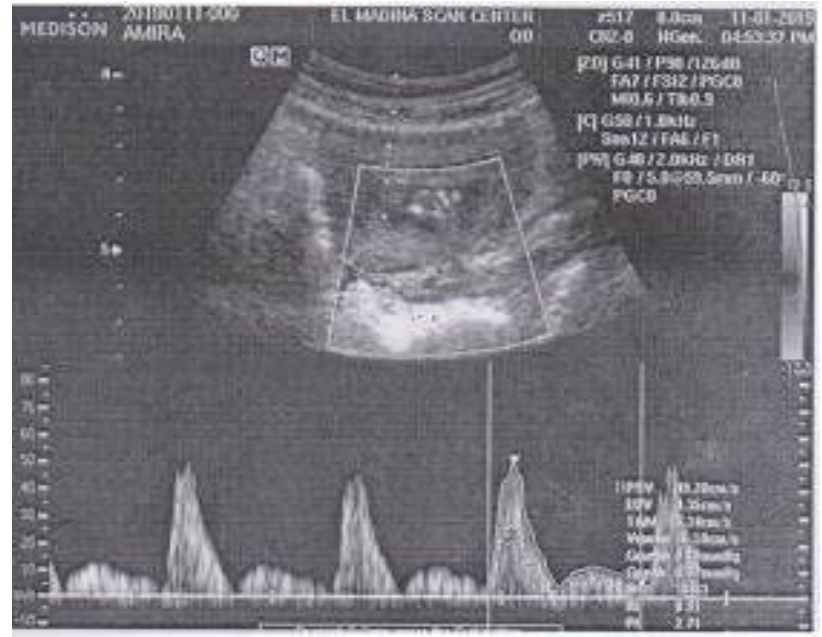

A

B

Figure (1): A. Normal uterine artery Doppler in first trimester. B. Abnormal uterine artery Doppler in first trimester.
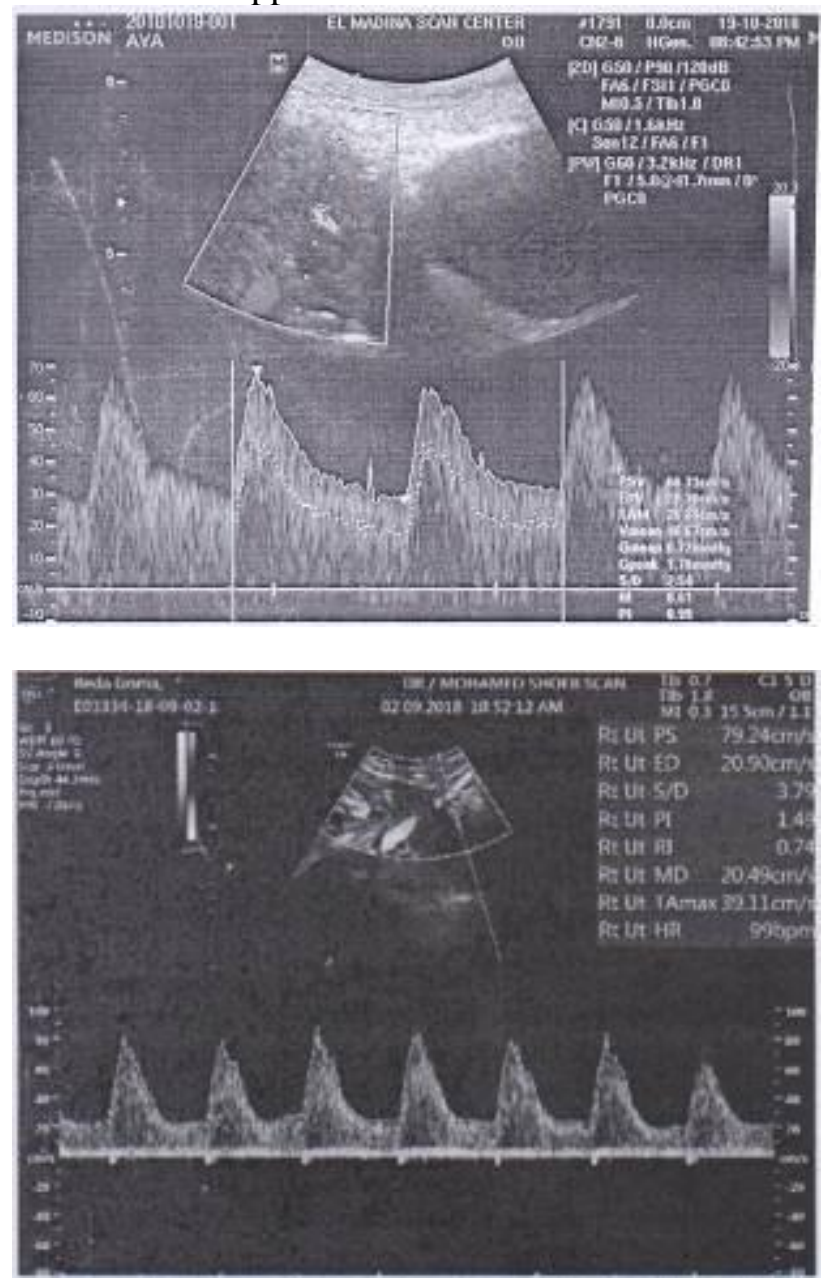

A

B

Figure (2): A. Normal uterine artery Doppler in second trimester. B. Abnormal uterine artery Doppler in second trimester.

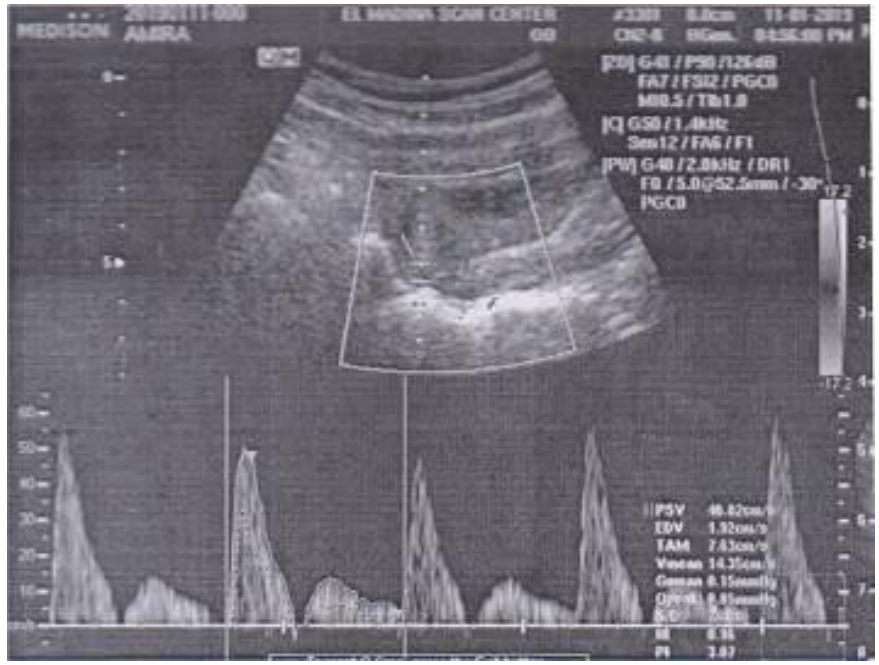

Figure (3): Diastolic notch of uterine artery.

\section{Statistical analysis}

Data were statistically described in terms of range, mean, standard deviation $( \pm \mathrm{SD})$, frequencies (number of cases) and relative frequencies (percentages) when appropriate. Comparison of quantitative variables between different groups in the present study was done using paired (to compare means of the same group during the first and second visit) and independent $\mathrm{t}$ - test (to compare the means of the 2 groups). For comparing categorical data, Chi square $\left(\mathrm{X}^{2}\right)$ test was performed. Yates correction was used instead when the expected frequency is less than 5. Accuracy was represented using the terms sensitivity, specificity, +ve predictive value, -ve predictive value and overall accuracy.

A probability value ( $p$ value) less than 0.05 was considered statistically significant. All statistical calculations were done using computer programs Microsoft Excel version 7 (Microsoft Corporation, NY, USA) and SPSS (Statistical Package for the Social Science; SPSS Inc., Chicago, IL, USA) statistical program.

\section{RESULTS}

Table (1): The age of the studied group (No $=60$ women) and $\beta$-HCG titre in the first visit (11-14 week).

\begin{tabular}{|c|c|c|}
\hline & Range & Mean \pm SD \\
\hline Age (years) & $20-27$ & $22.45 \pm 1.77$ \\
\hline & 11625 & \\
titter(mIU/ml) & 33888 & 46913.57 \\
& 0 & \\
\hline
\end{tabular}

$\mathrm{BMI}=$ Body mass index (weight in $\mathrm{kg} /$ height in $\mathrm{m}^{2}$ ). SBP=Systolic blood pressure, $\mathrm{DBP}=$ Diastolic blood pressure 
Table (2): Comparison between first and second visit as regard demographic data and uterine artery Doppler indicies.

\begin{tabular}{|c|c|c|c|c|}
\hline & & First visit (11-14) & Second visit (22-24) & P-value \\
\hline \multirow{2}{*}{ BMI $\left(\mathrm{kg} / \mathrm{m}^{2}\right)$} & Mean \pm SD & $24.40 \pm 1.89$ & $26.30 \pm 1.95$ & \multirow{2}{*}{$<0.001$} \\
\hline & Range & $19.2-28.7$ & $22.7-30.8$ & \\
\hline \multirow{2}{*}{$\mathrm{SBP}(\mathrm{mmHg})$} & Mean \pm SD & $107.67 \pm 7.67$ & $108.83 \pm 12.09$ & \multirow{2}{*}{0.560} \\
\hline & Range & $90-120$ & $90-150$ & \\
\hline \multirow{2}{*}{$\mathrm{DBP}(\mathrm{mmHg})$} & Mean \pm SD & $66.17 \pm 7.15$ & $66.33 \pm 8.02$ & \multirow{2}{*}{0.903} \\
\hline & Range & $60-90$ & $60-90$ & \\
\hline \multirow{2}{*}{$\begin{array}{l}\text { Right uterine } \\
\text { artery PI }\end{array}$} & Mean \pm SD & $1.73 \pm 0.38$ & $1.38 \pm 0.34$ & \multirow{2}{*}{$<0.001$} \\
\hline & Range & $0.68-2.62$ & $0.73-2.49$ & \\
\hline \multirow{2}{*}{$\begin{array}{l}\text { Left uterine } \\
\text { artery PI }\end{array}$} & Mean \pm SD & $1.67 \pm 0.35$ & $1.35 \pm 0.32$ & \multirow{2}{*}{$<0.001$} \\
\hline & Range & $0.85-2.6$ & $0.72-2.45$ & \\
\hline \multirow{2}{*}{$\begin{array}{l}\text { Right uterine } \\
\text { artery RI } \\
\end{array}$} & Mean \pm SD & $0.60 \pm 0.12$ & $0.59 \pm 0.10$ & \multirow{2}{*}{0.542} \\
\hline & Range & $0.41-0.86$ & $0.38-0.92$ & \\
\hline \multirow{2}{*}{$\begin{array}{l}\text { Left uterine } \\
\text { artery RI }\end{array}$} & Mean \pm SD & $0.59 \pm 0.08$ & $0.59 \pm 0.11$ & \multirow{2}{*}{0.796} \\
\hline & Range & $0.48-0.82$ & $0.37-0.93$ & \\
\hline \multirow{2}{*}{ Diastolic notch } & Absent & $49(81.7 \%)$ & $54(90.0 \%)$ & \multirow{2}{*}{0.191} \\
\hline & Present & $11(18.3 \%)$ & $6(10.0 \%)$ & \\
\hline
\end{tabular}

P-value >0.05: Non significant; P-value< 0.01: highly significant. BMI=Body mass index $\mathrm{SBP}=$ Systolic blood pressure $\mathrm{DBP}=$ Diastolic blood pressure $\mathrm{CRL}=$ Crown rump length $\mathrm{FL}=$ Femur length $\mathrm{PI}=$ pulsatility index RI=Resistance index.

Table (3): Comparison between normal and preeclampsia women regarding demographic characters, $\beta$-HCG and uterine artery Doppler indices at 11-14weeks.

\begin{tabular}{|c|c|c|c|c|}
\hline \multirow{2}{*}{\multicolumn{2}{|c|}{ First Visit (11-14w) }} & Normal & Preeclampsia & \multirow{2}{*}{ P-value } \\
\hline & & No. $=56(93.3 \%)$ & No. $=4(6.7 \%)$ & \\
\hline Age (years) & $\begin{array}{l}\text { Mean } \pm \text { SD } \\
\text { Range }\end{array}$ & $\begin{array}{c}22.38 \pm 1.67 \\
20-26\end{array}$ & $\begin{array}{c}23.50 \pm 3.00 \\
21-27\end{array}$ & 0.222 \\
\hline \multirow{2}{*}{$\operatorname{BMI}\left(\mathrm{kg} / \mathrm{m}^{2}\right)$} & Mean \pm SD & $24.43 \pm 1.78$ & $23.98 \pm 3.45$ & \multirow{2}{*}{0.648} \\
\hline & Range & $20.9-28.7$ & $19.2-26.8$ & \\
\hline \multirow{2}{*}{ SBP (mmHg) } & Mean \pm SD & $107.68 \pm 7.13$ & $107.50 \pm 15.00$ & \multirow{2}{*}{0.965} \\
\hline & Range & $90-120$ & $90-120$ & \\
\hline \multirow{2}{*}{$\mathrm{DBP}(\mathrm{mmHg})$} & Mean \pm SD & $65.54 \pm 6.30$ & $75.00 \pm 12.91$ & \multirow{2}{*}{0.009} \\
\hline & Range & $60-80$ & $60-90$ & \\
\hline \multirow{2}{*}{$\begin{array}{c}\beta \text { HCG titter } \\
(\mathrm{mIU} / \mathrm{ml})\end{array}$} & Mean \pm SD & $92303.62 \pm 48355.09$ & $99845.00 \pm 18600.49$ & \multirow{2}{*}{0.759} \\
\hline & Range & $11625-338880$ & $75500-120694$ & \\
\hline \multirow{2}{*}{$\begin{array}{l}\text { Right uterine } \\
\text { artery PI }\end{array}$} & Mean \pm SD & $1.69 \pm 0.34$ & $2.39 \pm 0.38$ & \multirow{2}{*}{$<0.001$} \\
\hline & Range & $0.68-2.51$ & $1.83-2.62$ & \\
\hline \multirow{2}{*}{$\begin{array}{l}\text { Left uterine } \\
\text { artery PI }\end{array}$} & Mean \pm SD & $1.62 \pm 0.29$ & $2.36 \pm 0.40$ & \multirow{2}{*}{$<0.001$} \\
\hline & Range & $0.85-2.1$ & $1.76-2.6$ & \\
\hline \multirow{2}{*}{$\begin{array}{l}\text { Right uterine } \\
\text { artery RI }\end{array}$} & Mean \pm SD & $0.59 \pm 0.11$ & $0.73 \pm 0.13$ & \multirow{2}{*}{0.020} \\
\hline & Range & $0.41-0.83$ & $0.58-0.86$ & \\
\hline \multirow{2}{*}{$\begin{array}{l}\text { Left uterine } \\
\text { artery RI }\end{array}$} & Mean \pm SD & $0.58 \pm 0.07$ & $0.74 \pm 0.11$ & \multirow{2}{*}{$<0.001$} \\
\hline & Range & $0.48-0.77$ & $0.59-0.82$ & \\
\hline \multirow{2}{*}{ Diastolic notch } & Absent & $48(85.7 \%)$ & $1(25.0 \%)$ & \multirow{2}{*}{0.002} \\
\hline & Present & $8(14.3 \%)$ & $3(75.0 \%)$ & \\
\hline
\end{tabular}

P-value >0.05: Non significant; P-value <0.05: Significant; P-value < 0.01: highly significant

$\mathrm{BMI}=$ Body mass index, $\mathrm{SBP}=$ Systolic blood pressure, $\mathrm{DBP}=$ Diastolic blood pressure, $\mathrm{CRL}=$ Crown rump length, PI=Pulsatility index, RI=Resistance index

Diastolic notch was significantly occurred in PE cases (75\% of women with first trimester notching develop PE). 
Table (4): Comparison between normal and preeclampsia regarding demographic characters and uterine artery Doppler at 22-24 week

\begin{tabular}{|c|c|c|c|c|}
\hline \multicolumn{2}{|c|}{ Second visit(22-24w) } & Normal & Preeclampsia & P-value \\
\hline \multirow{2}{*}{$\operatorname{BMI}\left(\mathrm{kg} / \mathrm{m}^{2}\right)$} & Mean \pm SD & $26.14 \pm 1.88$ & $28.50 \pm 1.78$ & \multirow{2}{*}{0.018} \\
\hline & Range & $22.7-30.4$ & $26.5-30.8$ & \\
\hline \multirow{2}{*}{$\mathrm{SBP}(\mathrm{mmHg})$} & Mean \pm SD & $107.32 \pm 9.81$ & $130.00 \pm 21.60$ & \multirow{2}{*}{$<0.001$} \\
\hline & Range & $90-130$ & $100-150$ & \\
\hline \multirow{2}{*}{$\mathrm{DBP}(\mathrm{mmHg})$} & Mean \pm SD & $65.18 \pm 6.03$ & $82.50 \pm 15.00$ & \multirow{2}{*}{$<0.001$} \\
\hline & Range & $60-80$ & $60-90$ & \\
\hline \multirow{2}{*}{ Right uterine artery PI } & Mean \pm SD & $1.35 \pm 0.30$ & $1.84 \pm 0.46$ & \multirow{2}{*}{0.004} \\
\hline & Range & $0.73-2.49$ & $1.21-2.31$ & \\
\hline \multirow{2}{*}{ Left uterine artery PI } & Mean \pm SD & $1.31 \pm 0.27$ & $1.81 \pm 0.60$ & \multirow{2}{*}{0.002} \\
\hline & Range & $0.72-1.73$ & $1.01-2.45$ & \\
\hline \multirow{2}{*}{ Right uterine artery RI } & Mean \pm SD & $0.58 \pm 0.09$ & $0.74 \pm 0.18$ & \multirow{2}{*}{0.002} \\
\hline & Range & $0.38-0.88$ & $0.51-0.92$ & \\
\hline \multirow{2}{*}{ Left uterine artery RI } & Mean \pm SD & $0.58 \pm 0.10$ & $0.74 \pm 0.17$ & \multirow{2}{*}{0.004} \\
\hline & Range & $0.37-0.89$ & $0.52-0.93$ & \\
\hline \multirow{2}{*}{ Diastolic notch } & Absent & $54(96.4 \%)$ & $0(0.0 \%)$ & \multirow{2}{*}{$<0.001$} \\
\hline & Present & $2(3.6 \%)$ & $4(100.0 \%)$ & \\
\hline
\end{tabular}

P-value $<0.05$ : Significant; P-value $<0.01$ : highly significant

$\mathrm{BMI}=$ Body mass index $\mathrm{SBP}=$ Systolic blood pressure $\mathrm{DBP}=$ Diastolic blood pressure FL=Femur length $\mathrm{PI}=\mathrm{Pulsatility}$ index RI=Resistance index

This table shows that there were significant statistical differences between both groups regarding weight, SBP, DBP, PI and RI of uterine arteries.

Also, diastolic notch was present in $100 \%$ of cases who developed PE later on.

Table (5): Comparison between normal and preeclampsia regarding diastolic notch

\begin{tabular}{|l|c|c|c|c|}
\hline & & Absent diastolic notch & Diastolic notch & P-value \\
\hline \multirow{3}{*}{$\mathbf{1}^{\text {st }}$ trimester } & Normal & $48(98.0 \%)$ & $8(72.7 \%)$ & \multirow{2}{*}{0.002} \\
& Preeclampsia & $1(2.0 \%)$ & $3(27.3 \%)$ & \\
\cline { 2 - 5 } & Total & $49(100.0 \%)$ & $11(100.0 \%)$ & \\
\hline \multirow{2}{*}{$2^{\text {nd }}$ trimester } & Normal & $54(100.0 \%)$ & $2(33.3 \%)$ & \multirow{2}{*}{$<0.001$} \\
& Preeclampsia & $0(0.0 \%)$ & $4(66.7 \%)$ & \\
\hline
\end{tabular}

P-value< 0.01: highly significant.

Diastolic notch was present in all cases who developed PE in second visit, while it was present in $75 \%$ of cases who developed PE in first visit.

Table (6): The relation between the diastolic notch and the pregnancy outcome

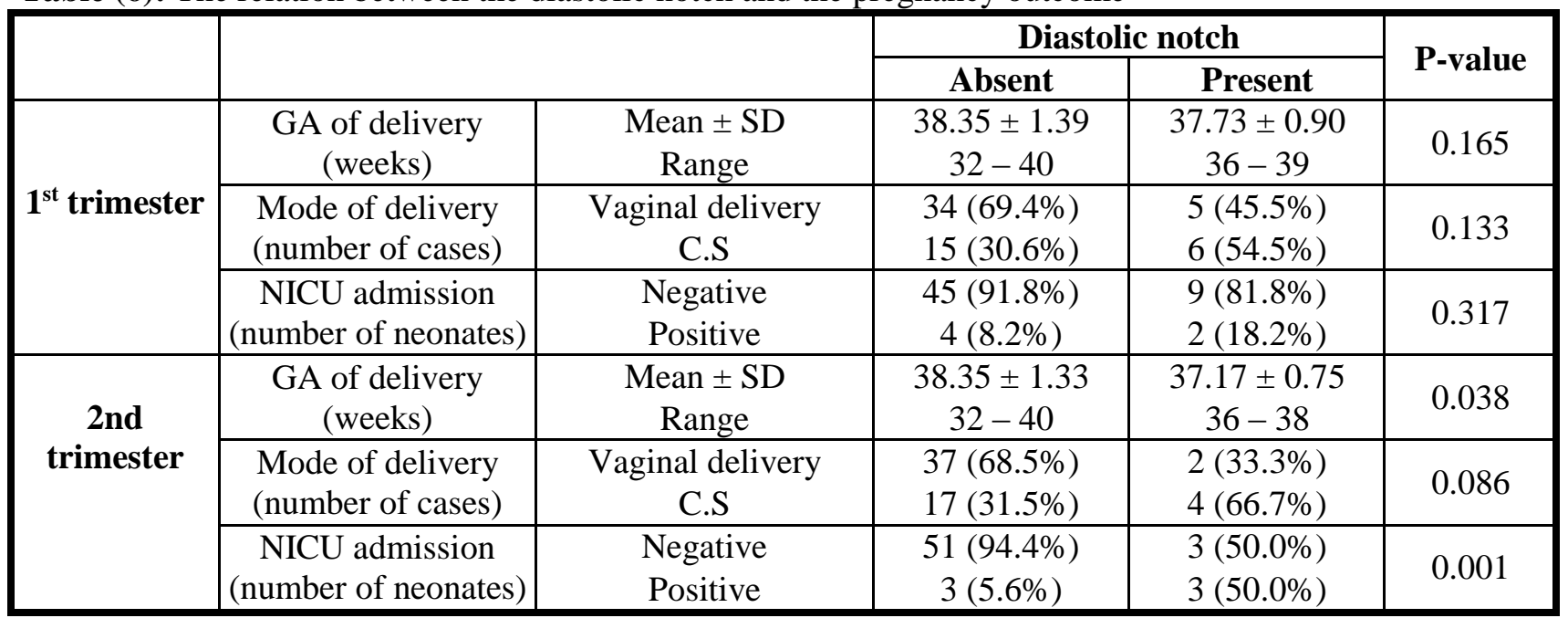

P-value >0.05: Non significant; $P$-value $<0.05$ : Significant; $P$-value $<0.01$ : highly significant

$\mathrm{GA}=$ Gestational age $\mathrm{CS}=$ Cesarean section NICU= Neonatal intensive care unit. This table shows that the presence of diastolic notch in the second trimester was significantly related to reduced gestational age at time of delivery and increased incidence of neonatal admission to neonatal intensive care unit. 
Table (7): Comparison between normal and preeclampsia regarding delivery outcomes

\begin{tabular}{|c|c|c|c|c|}
\hline \multicolumn{2}{|c|}{} & Normal & Preeclampsia & \multirow{2}{*}{ P-value } \\
\cline { 3 - 4 } & No. $=\mathbf{5 6}$ & No. $=\mathbf{4}$ & \\
\hline \multirow{2}{*}{$\begin{array}{l}\text { GA at the time of } \\
\text { delivery (Weeks) }\end{array}$} & $\begin{array}{c}\text { Mean } \pm \text { SD } \\
\text { Range }\end{array}$ & $\begin{array}{c}38.34 \pm 1.31 \\
32-40\end{array}$ & $\begin{array}{c}36.75 \pm 0.50 \\
36-37\end{array}$ & \multirow{2}{*}{0.020} \\
\hline $\begin{array}{c}\text { Mode of delivery } \\
\text { (number of cases) }\end{array}$ & $\begin{array}{c}\text { Vaginal } \\
\text { C.S }\end{array}$ & $\begin{array}{c}38(67.9 \%) \\
18(32.1 \%)\end{array}$ & $\begin{array}{c}1(25.0 \%) \\
3(75.0 \%)\end{array}$ & \multirow{2}{*}{0.083} \\
\hline $\begin{array}{c}\text { NICU admission } \\
\text { (Number of newborn) }\end{array}$ & $\begin{array}{c}\text { Negative } \\
\text { Positive }\end{array}$ & $\begin{array}{c}53(94.6 \%) \\
3(5.4 \%)\end{array}$ & $\begin{array}{c}1(25.0 \%) \\
3(75.0 \%)\end{array}$ & \multirow{2}{*}{$<0.001$} \\
\hline
\end{tabular}

P-value >0.05: Non significant; P-value $<0.05$ : Significant; P-value $<0.01$ : highly significant.

$\mathrm{NICU}=$ Neonatal intensive care unit $\mathrm{GA}=$ Gestational age $\mathrm{CS}=$ cesarean section

There was significant statistical difference between normal and PE groups regarding gestational age at the time of delivery. But there was insignificant statistical difference in both groups regarding mode of delivery. Most of neonates of mothers having PE (75\%) needed NICU admission.

\section{DISCUSSION}

Preeclampsia is a pregnancy-specific syndrome that occurs after mid-gestation. It is defined by the de novo appearance of hypertension (systolic blood pressure of $\geq 140 \mathrm{mmHg}$ or diastolic blood pressure of $\geq 90 \mathrm{mmHg}$ ), accompanied by new-onset proteinuria, defined as $\geq 300 \mathrm{mg}$ per 24 hours or persistent $30 \mathrm{mg} / \mathrm{dl}$ (1+ dipstick) in random urine samples ${ }^{(15)}$.

The current study was performed to determine the value of early pregnancy uterine artery Doppler ultrasonography and maternal serum $\beta$ human chorionic gonadotropin ( $\beta-\mathrm{HCG})$ in predicting the subsequent development of preeclampsia.

In this study, four women of the study group developed preeclampsia $(6.7 \%)$

In the current study, the BMI was significantly higher in women who developed PE than others, this means that the weight gain increased in cases who developed preeclampsia than others. This agreed with Kienast et al. ${ }^{16}$; Ning et al. ${ }^{17}$ and Rana et al. ${ }^{18}$, as they found that BMI was high in PE women.

Regarding the maternal serum $\beta-\mathrm{HCG}$, we found that the mean value of maternal serum $\beta$-HCG was not significantly changed in women who developed preeclampsia compared to those who did not develop PE. Our result was in agreement with Ning et al. ${ }^{17}$, who found that when maternal serum level of free $\beta$-HCG was measured at 11-13 weeks \pm 6 days of gestation, the $\beta$-HCG level was not significantly different in PE group than normal.

Also our results were in agreement with Dusica et al. ${ }^{19}$, who measured serum $\beta$-HCG from 11-14 weeks of gestation. Hypertensive disorders through pregnancy were diagnosed in $20.2 \%$ of cases. There was no significant difference $(P \geq 0.05)$ in $\beta$ HCG concentration between women with or without $\mathrm{GH} / \mathrm{PE}$.

Our result was in converse with the study of Johnson et al. ${ }^{20}$, who measured maternal serum $\beta$ human chorionic gonadotrophin levels at 7-13 weeks of gestation in 62 pregnancies conceived by in vitro fertilization and embryo transfer. They found significantly lower $\beta$-HCG levels in the eight women who developed preeclampsia.

Our result was also in converse with the study of Abdel Moety et al. ${ }^{21}$, who found that serum $\beta$-HCG was significantly reduced in patients who developed PE when compared with those who did not.

Ong et al. ${ }^{22}$, stated that a possible explanation for the apparent difference in serum concentrations of $\beta$ HCG during the first and second trimesters in pregnancies developing later preeclampsia is that the low levels at 10-14 weeks are the consequence of impaired placentation and smaller placental mass. Whereas the high levels in the second trimester may be the result of hypoperfusion related stimulation of production of this hormone.

We examined the uterine artery Doppler at 11-14 weeks of gestation. The mean pulsatility index (PI) and resistance index (RI) of both right and left uterine arteries were significantly higher in PE group.

Regarding the diastolic notch, its frequency was significantly higher in preeclampsia group.

This was in agreement with Poon et al. ${ }^{23}$, who reported that in women who subsequently developed PE, the uterine artery PI were significantly higher than in control group. The detection rate for early preeclampsia improved to $83.8 \%$ using first trimester uterine artery Doppler.

Our result are in agreement with Abdel Moety et al. ${ }^{21}$, who measured uterine artery Doppler for patients from 11-14 weeks. Uterine artery PI and RI were significantly higher in patients who developed complications when compared with those who did not. Uterine artery PI had the highest sensitivity $(100 \%)$ but a low specificity $(56 \%)$ in prediction of preeclampsia.

Our results were in agreement with Diguisto et al. ${ }^{24}$, who found that among women developed PE the lowest pulsatility index was high $(\mathrm{p}=0.02)$ and 
bilateral notching was more frequent. They were also in agreement with Mittal et al. ${ }^{25}$, who found that the first trimester uterine artery mean resistance index (RI) and mean pulsatility index (PI) were significantly higher in patient developed $\mathrm{PE}$ and IUGR, and with Rana et al. ${ }^{18}$, who found that all Doppler indices PI and RI had high specificities and NPV. Specificity of RI came out to be $95.5 \%$ with NPV $91.4 \%$ and the specificity and NPV of PI were $93.3 \%$ and 90.2 respectively. They also agreed with Yildirm et al. ${ }^{26}$, who found that the uterine artery PI was statistically higher in preeclampsia than normal $(\mathrm{p}<0.05)$.

Our results were in contrast with Casmod $\boldsymbol{e t}$ al. ${ }^{27}$, who found that PI do not act well as a predictor of PE. As in the first trimester Doppler study seven women had mean PI value above $50^{\text {th }}$ percentile and only one case developd preeclampsia. They were also in contrast with Mittal et al. ${ }^{25}$, who found that there was not a significant relation between preeclampsia, and the presence of diastolic notch because of the high prevalence of this finding in early pregnancy, and with the study of Allen and Aquilina ${ }^{28}$, who found no statistically significant association between the level of mean uterine artery PI and development of preeclampsia. As their study had low incidence of early onset preeclampsia.

In the current study, in the second trimester Doppler study at 22-24 weeks of gestation; it was found that, PI and RI of both uterine arteries were significantly higher in those developed PE than those who didn't develop preeclampsia.

The diastolic notch was highly significantly more in the PE group. This was in agreement with Arriaga et al. ${ }^{29}$, who found that the higher uterine artery PI in the second trimester was associated with PE and FGR, and with Kiensat et al. ${ }^{16}$ and Uharcer et al. ${ }^{30}$, who proved that development of PE over all was associated with increase PI and RI.

This result was in agreement with the study of Ning et al. ${ }^{17}$, who measured the uterine artery PI at 22-24 weeks gestation. Patients who developed PE had significantly higher uterine artery PI compared to control group. In that study the sensitivity of PI was $52 \%$ with diagnostic accuracy $76 \%$. It is also in agreement with Chyad $\boldsymbol{e t}$ al. ${ }^{31}$, who found that there was a statistically significant difference between PE and non PE according to level of uterine artery RI and PI in right and left sides. In this study the sensitivity of RI was $90 \%$, specificity was $87 \%$, PPV was $75 \%$, NPN was $95.2 \%$ with diagnostic accuracy of $87 \%$. While the sensitivity of PI was $60 \%$, specificity was $87 \%$ PPV was66.7\%, NPV was $83.3 \%$ with diagnostic accuracy 78.8 .

In the current study, regarding to PE rate in the presence of notch in the second visit, $66 \%$ of cases having diastolic notch developed preeclampsia. It was significantly higher than that in non-notch group. This was in agreement with Guo et al. ${ }^{32}$, who found that PE incidence rate of notch group was significantly higher than that in non notch group and the difference in PE incidence rate of two group was statistically significant and also in agreement with Casmod et al. ${ }^{26}$, who stated that the presence of notching in the second trimester was associated with high probability of developing preeclampsia.

In contrast to the current study, the presence or absence of notch was not found to be statistically significant in the studies performed by Martin $\boldsymbol{e t}$ al. ${ }^{33}$ and Dugoff et al. ${ }^{34}$.

In the current study, in the first trimester, the values of uterine artery PI and RI were significantly higher in preeclampsia and the cut off value of right uterine artery PI was > 2.21 and had the following sensitivity, specificity, PPV and NPV: Sensitivity $=75 \%, \quad$ Specificity $=98.21 \%, \quad \mathrm{PPV}=75 \% \quad$ and $\mathrm{NPV}=98.2 \%$. The cut off value of left uterine artery PI was > 2.1 and had the following sensitivity, specificity, PPV and NPV: Sensitivity $=75 \%$, Specificity $=100 \%, \mathrm{PPV}=100 \%$ and NPV $=98.2 \%$.

The cut off value of right uterine artery RI was > 0.57 and had the following sensitivity, specificity, PPV and NPV: Sensitivity $=100 \%$, Specificity $=64.29 \%, \mathrm{PPV}=16.7 \%$ and $\mathrm{NPV}=100 \%$. The cut off value of left uterine artery RI was $>0.69$ and had the following sensitivity, specificity, PPV and NPV: Sensitivity $=75 \%$, Specificity $=89.2 \%$, $\mathrm{PPV}=33.3 \%$ and $\mathrm{NPV}=98 \%$.

In contrast to the current study, the study of Mittal et al. ${ }^{25}$, who found that in the first trimester the uterine artery mean PI and mean RI were significantly higher in PE, but they found in their study the mean RI was a better predictor than the mean PI. According to ROC analysis the cut off value of RUA PI was 1.5, LUA PI was 1.4 and the cut off values of RUA RI was 0.65 and LUA RI was 0.65 .

In the current study, in the second trimester, the values of uterine artery RI and PI were significantly higher in preeclampsia than non preeclampsia cases. The cut off value of right uterine artery PI was > 1.58 and had the following: Sensitivity $=75 \%$, Specificity $=98.21 \%$, PPV $=75 \%$ and NPV $=98.2 \%$. The cut off value of left uterine artery PI was > 1.73 and had the following: Sensitivity $=75 \%$, Specificity $=100 \%$, PPV $=100 \%$ and NPV $=98.2 \%$. The cut off value of right uterine artery RI was > 0.67 and had the following: Sensitivity $=75 \%$, Specificity $=94.64 \%, P P V=50 \%$ and NPV $=98.1 \%$. The left uterine artery RI cut off value was $>0.7$ and had the following: Sensitivity $=75 \%, \quad$ Specificity $=91.07 \%, \quad \mathrm{PPV}=37.5 \% \quad$ and $\mathrm{NPV}=98.1 \%$.

In contrast Emine et al. ${ }^{35}$, found that the maternal uterine artery Doppler at the second trimester had a significant predictive values for PE and the presence of diastolic notch had the highest 
combination of sensitivity 85.7 , specificity 97.6 and predicted $96.6 \%$ of cases. Uterine artery RI cut off value was 0.62 with sensitivity $78.6 \%$, specificity $86.6 \%$, PPN $33.3 \%$, NPV $97.9 \%$ and predicted $86 \%$ of cases.

Ning et al. 17, found that uterine artery Doppler PI sensitivity was 52\% and predicted $76 \%$ of cases. They found that sensitivity of UTAD PI increased to $72 \%$ and predicted $89 \%$ of cases after addition of first trimester biomarker (PAPPA and ADAM12).

Chyad et al. ${ }^{31}$, found the uterine artery RI cut off value was 0.7 . The sensitivity of uterine artery RI was $90 \%$, specificity was $87 \%$, PPV was $75 \%$, NPV was $90.2 \%$ and predicted correctly $87 \%$ of cases. The PI cut off value was 1.4 , the sensitivity of uterine artery PI was $60.5 \%$, specificity $87 \%$, PPV $6.7 \%$, NPV $83.3 \%$ and predicted correctly $78.8 \%$ by uterine artery Doppler performed at 14-20 weeks of gestation.

\section{CONCLUSION}

The high maternal uterine artery pulsatility index (PI) and resistant index (RI) in early pregnancy (11-14 weeks of gestation) and in mid pregnancy (2224 weeks of gestation) were associated with occurrence of preeclampsia.

$75 \%$ of preeclampsia cases had diastolic notch in 11-14 weeks of gestation and all preeclampsia cases had diastolic notch in 22-24 weeks of gestation. So it is a good predictor for preeclampsia.

Maternal serum $\beta$-HCG titre was insignificant marker for the prediction of preeclampsia.

\section{REFERENCES}

1. Uzan J, Carbonnel M, Piconne O, Asmar R, Ayobi JM (2011): Preeclampsia: pathophysiology, diagnosis, and management. Vascular health and risk management,7: 467474.

2. Robert JM, Cooper DW (2001): Pathogenesis and genetic of preeclampsis. Lancet, 357: 53-6.

3. McMaster MT, Zho U, Fisher SJ (2004): Abnormal placentation and the syndrome of preeclampsia. Seminar Nephropathy, 24(6): 540- 547.

4. Majumdar $S$, Dasgupia $H$, Bhattacharya $K$, Bhattacharya A (2005): A study of placenta in normal and hypertensive pregnancies. J Ant Soc India, 54(2): 1-9.

5. Kuklina EV, Ayala C, Callaghan WM (2009): Hypertensive disorders and severe obstetric morbidity in the United States. Obstetrics\&Gynecology,113(6): 12991306.

6. Cole LA, Kardana A, Park SY, Braunstien GD (1993): Te deactivation of HCG by nicking and dissociation. Journal of Clinical endocrinology and metabolism, 76(3): 704-710

7. Kurtzman JT, Wilson H, Rao CV (2001): A proposed role for HCG in clinical obstetrics. https://europepmc.org/abstract/med/11394205
8. Zygmunt M, Herr F, Keller-Schoenwetter S (2002): Characterization of human chorionic gonadotropin as a novel angiogenic factor. Journal of Clinical Endocrinology and Metabolism, 87(11): 5290-5296.

9. Gurbuz A, Karateke A, Mengulluoglu M, Gedikbasi A, Ozturkmen M, Kabaca C (2004): Can serum HCG values be used in the differential diagnosis of pregnancy complicated by hypertension? hypertense pregnancy,23(1): 1-12.

10.Bartha JL, Romero- Carmona R, Escobar- Liompart M, Paloma-Castro O, Comino- Delgado R (2003): Human chorionic gonadotropin and vascular endothelial growth factor in normal and complicated pregnancies Obstetrics \& Gynecology, 102: 955-999.

11.Ghidini A, Locatelli A (2008): Monitoring of foetal well being: role of uterine artery. Seminars in perinatology,32(4): 258- 262.

12. Schulman H, Fleisesher A, Farmakids G, Bracero L, Grunfeld L (1986), development of uterine artery compliance in pregnancy as detected by Doppler ultra-sound. American Journal of Obstetrics and gynecology,155(5): 1031-1036.

13. Yang JM, Yang YC, Wang KG (1996): central and peripheral haemodynamics in sever preeclampsia. Act a Scandinavin Obstetrics and. Gynecology, 75(2): 120-60.

14. Giordano R, Caccyated A, Romano M, La Rosa $B$ and Vigna R(2010).Uterine artery Doppler flow study in obstetric practice. Journal of prenatal medicine, 4(4):59.

15. Sibai B, Dekker G, Kupferminc M (2005): Preeclampsia. Lancet, 365: 785-799.

16. Kienast C, Moya W, Rodriguez O, Jijón A, Geipel A (2016): Predictive value of angiogenic factors, clinical risk factors and uterine artery Doppler for pre-eclampsia and fetal growth restriction in second and third trimester pregnancies in an Ecuadorian population. The Journal of Maternal-Fetal \& Neonatal Medicine, 29(4): 537-43.

17. Ning Y, Hongyan C, Xu C, Ying C (2017): First trimester serum anylates and second trimester uterine artery Doppler in the prediction of preeclampsia and fetal growth restriction. Taiwanese Journal of Obstetrics and Gynecology, 56(3): 358-361.

18. Rana UB, Minhas S, Negi P, Patania K, Kaur SP (2017): To stud the association of Doppler derived indices of uterine artery resistance with composite of PIH/PET. International Journal of Reproduction, contraception, obstetrics and Gyneclogy, 6(3): 920..

19. Dusica KB, Ana SR, Snezana P, Jelena D, Slavica A, Mirjana MC and Alexander K (2019): Biochemical marker for prediction of hypertensive disorder of pregnancy. Journal of Medical Biochemstry, 38:71-82.

20. Johnson MR, Riddle AF, Sharma V, Colloins WP, Nicolaides KH (1993): The role of trophoblast dysfunction in the etiology of miscarriage. British journal of Obstetrics and. Gynecology, 100(4): 353-359.

21. Abdel Moety GAF, Almohamady M, Sherif NA (2015): Could first-trimester assessment of placental functions predict preeclampsia and intrauterine growth restriction? A prospective cohort study. The Journal of Maternal-Fetal \& Neonatal Medicine, 29(3):413-417.

22. Ong CY, Liao AW, Spencer K, Munim S, Nicolaides KH (2000): First trimester maternal serum free $\beta$ human chorionic gonadotrophin and pregnancy associated plasma protein A as predictors of pregnancy complications. BJOG: An International Journal of Obstetrics \& Gynaecology, 107(10): 1265-1270. 
23.Poon LC, Akolekar R, Lachmann R, Beta J, Nicolahdes KH (2010): Htpertensive disorders in pregnancy screening by biophysical and biochemical markers at 11-13weeks. Ultrasound in Obstetrics and Gynecology,35(6).662-670.

24. Diguisto C, Priver E, Le Gouge A, Eboue F, Le Vaillant C, Marechaud M (2016): First trimester uterine artery Doppler, sFlt-1 and PLGF to predict preeclampsia in high risk population, The Journal of Maternal- Fetal \&Neonatal Medicin, 30(13): 1514-9.

25. Mittal N, Priya P, Sharma N, Vishwakarma S (2016): Color Doppler study of uterine artery between 10-14 weeks of gestation as a predictor of intra-uterine growth restriction and preeclampsia. International Journal for Reproduction contraception and Gynecology, 58: 27842790.

26. Yildirm S, Cakiiroglu Y, Ceylan Y, Baki M (2018): Uterine artery Doppler Examination at 11-13+6 weeks of pregnancy and prediction of preeclampsia by PLGF, Endoglin and PAPPA level in maternal serum. European Medical Research, 13(6): 111-136.

27. Casmod Y, van Dyk B, Nicolaou E (2016): Uterine artery Doppler screening as apredictor of preeclampsia. https://www.researchgate.net/.../324642348_Uterine_artery_D oppler_screeni...

28. Allen R, Aquilina J (2017): Prospective observational study to determine the accuracy of first trimester serum biomarkers and uterine artery Doppler in combination with maternal characteristics and arteriography for the prediction of women at risk of preeclampsia and other adverse pregnancy outcomes. The Journal of Maternal Fetal \& Neonatal Medicin, 31(21): 2789-2806.

29. Comez-arriaga A, Herriaz I, Lopez-Jimenez EA, Gomez-Montes E, Denk B, Galindo A (2013): Uterine artery Doppler and sFlt-1/PLGF ratio usefulness in diagnosis of preeclampsia. Ultrasound in Obstetrics and Gynecology, 41(5): 530-537.

30. Uharcer P, Manova A, Brestansky A, Zajacova M, Ravinger J (2016): Prediction of preeclampsia and IUGR by uterine artery Doppler sonography. $26^{\text {th }}$ World congress on ultrasound in Obstetrics and Gynecology. Electronic Poster abstracts, 15(48), 342-343.

31. Chyad MA, Azab EA, Shalaby MA, Aly AA (2018): The role of uterine artery Doppler sonography in predicting pre-eclampsia at 14-20 weeks of gestation. The Egyptian Journal of Hospital Medicine, 73(11): 7850-7859.

32. Guo XJ, Ni X, Huang Y, Gu H (2016): Correlation of mid- pregnancy uterine artery notch with preeclampsia incidence risk as well as serum endothelial injury and placental hypoperfusion. Journal of Hainan Medical University, 22(20): 106-109.

33. Martin AM, Bindra R, Curcio P, Cicero S, Nicolaides KH (2001): Screening for pre-eclampsia and fetal growth restriction by uterine artery Doppler at 11-14 weeks of gestation. Ultrasound in Obstetrics \& Gynecology, 18(6): 583-586.

34. Dugoff L, Lynch AM, Cioffi-Ragan D (2005): FASTER Trial Research Consortium. First trimester uterine artery Doppler abnormalities predict subsequent intrauterine growth restriction. American Journal of Obstetrics and Gynecology, 193(32): 1208-1212.

35. Emine AY, Zehra NK, Koray EL, Husnus G, Tanju P (2005): screening for preeclampsia by using maternal serum inhibin A, activin A, human chorionic gonadotropin , un conjugated estriol, and alpha fetoprotein levels and uterine artery Doppler in the second trimester of pregnancy. Australian and New Zeland Journal of obstetrics and Gynecology, (45): 283-288. 